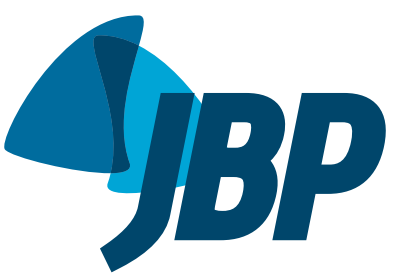

\title{
COPD: more treatment will translate to better breathing. Will it?
}

\author{
Paulo José Zimermann Teixeira ${ }^{1,2,3, a}$, Marcelo Ferreira Nogueira ${ }^{2,3, b}$
}

COPD is the third leading cause of death from a chronic noncommunicable disease in Brazil, and its prevalence varies by region, depending on the prevalence of smoking.(1) The treatment was previously very limited, based on short-acting bronchodilators, xanthines, and inhaled corticosteroids (ICS), as well as oral corticosteroids for very severe cases. However, the treatments have now, after a few years, become more broad and effective. Gaining precise knowledge of the indications, limitations, and potential risks/benefits of each treatment poses a challenge, because it is necessary to modify the simplistic thinking of those who insist on maintaining the ICS for all patients and the passivity of those who do not consider long-acting muscarinic antagonists (LAMAs) an option. The fee schedule of the Brazilian Sistema Único de Saúde (SUS, Unified Health Care System) has not been readjusted for several years, because, in the minds of managers, doctors and hospitals will always solve all of the problems. Therefore, the technicians responsible for the treatment protocols need to know that COPD patients can breathe better after the proposed treatment, despite the fact that there is not always evidence of a reduction in mortality. In fact, there is already a large body of evidence that justifies modifying the way we view and treat COPD patients in public and private clinical practice in Brazil. ${ }^{(2,3)}$

In this issue of the JBP, Pinto et al. ${ }^{(4)}$ demonstrate, with great elegance, the regrettable state of COPD treatment in the public health care system in Brazil. Theirs was a cross-sectional study involving patients diagnosed, on the basis of the clinical and spirometric findings, with moderate to severe COPD. All of the patients were referred from the SUS-affiliated Bahia State Public Health Care Network to a referral outpatient clinic. The authors demonstrated the reality of the SUS, emphasizing that the approach differs among states, ${ }^{(4)}$ because it depends heavily on the economic condition, although there have been attempts by several state societies to sensitize managers to the need to create treatment protocols for patients with COPD.

Pinto et al. ${ }^{(4)}$ included 383 patients, classified by risk of exacerbation and severity according to the Global Initiative for Chronic Obstructive Lung Disease (GOLD) criteria (risk group A, B, C, or D) and the Brazilian National Ministry of Health criteria (moderate, severe, or very severe), respectively. The authors questioned the patients about the use of COPD medications, subsequently assessing the appropriateness of the treatment (to identify undertreatment or overtreatment) in relation to national and international guidelines. The majority of the patients (70.5\%) belonged to the highest risk group (GOLD group D), and $48.8 \%$ of the patients were in the severe group according to the spirometric criteria. Pinto et al. ${ }^{(4)}$ found that $63.7 \%$ of patients in their sample were not treated in accordance with the Brazilian national guidelines (i.e., were treated inappropriately). The authors identified cases of undertreatment in their sample. Only half of the patients were using a long-acting bronchodilator. In addition, although $80 \%$ of the patients had a Medical Research Council dyspnea scale score $\geq 2$ and $85.1 \%$ of the sample had a high risk of exacerbation (GOLD group C or D), in which case the use of a LAMA is definitely indicated, only $9.7 \%$ of the sample were using one. In addition, more than half of the undertreated patients were using no medication, perhaps indicating a failure of guidance regarding the importance of continued treatment. A study conducted in the Brazilian state of Santa Catarina and involving 50 hospitalized patients showed that, in relation to the national guidelines, $74 \%$ were receiving inappropriate treatment and $38 \%$ were being undertreated. ${ }^{(5)}$ Another study, conducted in the state of Rio Grande do Sul, ${ }^{(6)}$ collected data related to 161 patients with COPD who were referred for pulmonary rehabilitation, most of them from the SUS-affiliated outpatient clinics of two institutions. ${ }^{(6)}$ In that study, $51.3 \%$ of the patients classified as being in GOLD group A were receiving an ICS unnecessarily and only $35.2 \%$ of those classified as being in GOLD group $D$ were receiving a long-acting $\beta_{2}$ agonist (LABA) combined with a LAMA and an ICS (LABA+LAMA+ICS), whereas $82.1 \%$ and $95.2 \%$ of those classified as being in GOLD groups $C$ and $D$, respectively, were receiving treatment that was in agreement with the GOLD recommendations.

In the Pinto et al. study, ${ }^{(4)}$ overtreatment (represented by the overuse of ICS) was significantly more common in patients with moderate COPD and in those at a lower risk of exacerbation, being identified in more than half of the individuals in the GOLD A and B groups (54.5\% and $54.3 \%$, respectively), as well as in $46.2 \%$ of the patients with moderate COPD. In addition to the underuse of long-acting bronchodilators and the overuse of ICS, as were quite well demonstrated by the authors, factors such as a low level of education, low income, not using oxygen therapy, and not having received the influenza vaccination have also been associated with inappropriate treatment of COPD. ${ }^{(5)}$

The current recommendation for COPD treatment is based on an accurate diagnosis and on phenotypic

1. Departamento de Clínica Médica, Disciplina de Pneumologia, Universidade Federal de Ciências da Saude de Porto Alegre, Porto Alegre (RS) Brasil.

2. Pneumologista do Pavilhão Pereira Filho, Santa Casa de Porto Alegre, Porto Alegre (RS) Brasil.

3. Programa de Pós-Graduação em Ciências da Saúde, Universidade Federal de Ciências da Saude de Porto Alegre, Porto Alegre (RS) Brasil.

a. (iD) http://orcid.org/0000-0002-4906-6970; b. (iD) http://orcid.org/0000-0003-1765-3123 
characteristics, especially whether or not the patient is a frequent exacerbator. In a recent review ${ }^{(3)}$ it was recommended that, in patients with severe dyspnea and a low risk of exacerbation, dual bronchodilator treatment (LABA+LAMA) is indicated. A recent metaanalysis showed that the use of the LABA+LAMA+ICS combination reduced the risk of exacerbation $(R R=$ $0.70 ; 95 \% \mathrm{CI}: 0.53-0.94$ ) and improved $\mathrm{FEV}_{1}$ (mean increase, $37.94 \mathrm{~mL}$; 95\% CI: 18.83-53.89) when compared with the use of the LABA+LAMA combination. ${ }^{(7)}$ However, triple therapy was found to have a protective effect mainly in the patients who had an eosinophil count $\geq 300$ cells $/ \mu \mathrm{L}$ ( $R R=0.57 ; 95 \% \mathrm{CI}: 0.48-0.68$ ). In that same meta-analysis, ${ }^{(7)}$ the authors concluded that patients on long-term bronchodilator therapy or using the LABA+LAMA combination who continue to experience exacerbations and have an eosinophil count $\geq 300$ cells $/ \mu \mathrm{L}$ would benefit from the triple therapy (LABA+LAMA+ICS). The risk of pneumonia was not found to be higher among the patients on triple therapy than among those on monotherapy or dual therapy.
Now that we have the new combinations of LABA+LAMA and LABA+LAMA+ICS, tailoring the treatment will be of fundamental importance. It is always important to emphasize that the pharmacological treatment of COPD should be complemented by measures such as smoking cessation, encouraging physical activity, pulmonary rehabilitation, and vaccination. ${ }^{(3)}$ However, all of the new evidence that is being unveiled will have no value if the knowledge is not disseminated. We cannot risk having primary care physicians who think that every wheezing patient has asthma and that there is no justification for performing spirometry (because the only treatment option is LABA+ICS) and who believe that (because LAMA has been approved for asthma) prescribing LABA+LAMA+ICS will resolve everything. We want to avoid the phenomenon in the pattern of prescribing treatment for COPD that occurred in the United Kingdom, in which all of the patients were moved from LABA+ICS to LABA+LAMA+ICS, ${ }^{(8)}$ a change that should not be made without clear, well-defined criteria. In conclusion, although undertreatment can worsen breathing, overtreatment will not necessarily improve breathing.

\section{REFERENCES}

1. Brasil. Ministério da Saúde. Secretaria de Políticas de Saúde. Departamento de Atenção Básica. Doenças respiratórias crônicas. Cadernos de Atenção Básica. no. 25. Brasília: Ministério da Saúde 2010

2. Global Initiative for Chronic Obstructive Lung Disease (GOLD) [homepage on the Internet]. Bethesda: GOLD [cited 2019 Jan 10] Global Strategy for the Diagnosis, Management, and Prevention of COPD - 2019 Report. [Adobe Acrobat document, 155p.]. Available from: https://goldcopd.org/wp-content/uploads/2018/11/GOLD2019-v1.7-FINAL-14Nov2018-WMS.pdf

3. Fernandes FLA, Cukier A, Camelier AA, Fritscher CC Costa CHD, Pereira EDB, et al. Recommendations for the pharmacological treatment of COPD: questions and answers. J Bras Pneumol. 2017;43(4):290-301. https://doi.org/10.1590/s180637562017000000153

4. Pinto CR, Lemos ACM, Assunção-Costa LA, Alcântara AT, Yamamura LLL, Souza GS, et al. Management of COPD within the Brazilian Unified Health Care System in the state of Bahia: an analysis of real- life medication use patterns. J Bras Pneumol. 2019;45(1):e20170194

5. Giacomelli IL, Steidle LJ, Moreira FF, Meyer IV, Souza RG, Pincell MP. Hospitalized patients with COPD: analysis of prior treatment J Bras Pneumol. 2014;40(3):229-37. https://doi.org/10.1590/S180637132014000300005

6. Teixeira PJZ, Huber A, Colombo C, Canterle DB, Souza RM, Zulkosk $A L$, Costa CC. Concordância entre o tratamento preconizado pelo GOLD 2011 e o tratamento farmacológico utilizado J Bras Pneumol. 2013;39(Suppl 1R):R9-R9

7. Cazzola M, Rogliani P, Calzetta L, Matera MG. Triple therapy versus single and dual long-acting bronchodilator therapy in chronic obstructive pulmonary disease: a systematic review and metaanalysis. Eur Respir J. 52(6). pii: 1801586.

8. Brusselle G, Price D, Gruffydd-Jones K, Miravitlles M, Keininger DL, Stewart $R$, et al. The inevitable drift to triple therapy in COPD: an analysis of prescribing pathways in the UK. Int $\mathrm{J}$ Chron Obstruct Pulmon Dis. 2015;10:2207-17. 